\title{
International Journal of Business and Administrative Studies
}

volume 5 issue 3 pp. 155-176 doi: https://dx.doi.org/10.20469/ijbas.5.10005-3

\section{Targeting Poor Students With Proxy Means Test}

\author{
Tapanat Paiboonsin * \\ Faculty of Economics, Thammasat University, \\ Bangkok, Thailand
}

\begin{abstract}
Proxy Means Test (PMT) is one of the most efficient ways to target the poor. The procedure of PMT is using household characteristic variables, which have a relationship with income, as a proxy for poverty. PMT is a measurement of wealth, that is so to say poverty without using income, consumption, or expenditure. In this study, we created the PMT poverty scorecard to be used as a tool for targeting poor student in 10 provinces of Thailand, including Mae Hong Son, Nan, Nakhon Ratchasimi, Udon Thani, Nakhon Phanom, Chiang Rai, Trung, Kanchanaburi, Chanthaburi, and Phuket. We estimated the relationship between these household characteristic variables and students' average monthly household income per capita using Ordinary Least Square (OLS) regression separately by the province to capture any geographical characteristic in each province. We then turned 11 household characteristic estimated coefficients into a PMT poverty scorecard for each province. Overall, the result suggests that PMT poverty targeting works well in 10 provinces of Thailand regarding low under coverage rate, high targeting accuracy rate in both poverty and total accuracy, except for Phuket, which has a huge leakage rate since its geographical characteristics are quite different compared to others. However, this leakage problem needs to be explored more as student maybe, in fact, actually poor as same as PMT poverty targeting suggested. For policy recommendation, we suggested using PMT as the main poverty targeting approach and an identification survey of students who have been targeted as poor to increase the efficiency of poverty targeting. Also, we suggested that adding household characteristic variables in the survey questionnaire could increase the efficiency of PMT poverty targeting in statistical terms.
\end{abstract}

Keywords: PMT, poverty scorecard, poverty targeting, household characteristics, geographical characteristics

Received: 29 April 2019; Accepted: 22 May 2019; Published:21 June 2019

\section{INTRODUCTION}

\section{Statement of the Problem}

Targeting the poor has become an important question as Conditional Cash Transfers (CCT) program, designed to help the poor escape from poverty, has become popular in many countries around the world. Some of those successful programs, for example, Prospera, formally known as Progresa/Oportunidades in Mexico and Bolsa Familia in Brazil. While transfers without conditional (Unconditional Cash Transfers: UCT) could achieve only one goal per program, usually increasing consumption or expenditure of benefiters, multiple goals could be achieved through conditional transfers since benefiters must obey the conditions, or else they might be excluded from the program. In economics, the total effect of the CCT comes from 2 components. One is from the condition considering as the substitution effect, and another one is, obviously, the income effect (Baird, Ferreira, Özler, \& Woolcock, 2014).

The first question in this program is that: should the transfer be universal, where everyone in country receives transfer equally or targeting transfer to some group such as the poor? Although universal transfer is easy to distribute

${ }^{*}$ Correspondence concerning this article should be addressed to Tapanat Paiboonsin, Faculty of Economics, Thammasat University, Bangkok, Thailand E-mail: tapanatpong@gmail.com

(c) 2019 The Author(s). Published by KKG Publications. This is an Open Access article distributed under a Creative Commons Attribution-NonCommercial-NoDerivatives 4.0 International License. 
transfers and cost-less to administrative, it is usually questionable since everyone has a chance of receiving this transfer whether they are poor or not. This type of transfer usually comes together with UCT.

If one chooses to transfer cash via a targeting transfer policy, which usually comes together with CCT, the important question of this study now arises: how to target the poor? The poorly targeting can cause a serious problem of horizontal equity since some of the poor might not receive transfer while in fact, they are eligible. Such a problem is called Exclusion error. While another error: Inclusion error occurs when the non-poor receives transfer causing a budget leakage problem also.

One reasonable measurement to targeting the poor is to use their income, consumption, or expenditure, which is called a Means test. This measurement, however, only works well in developed countries because these data are usually not available in developing countries for many reasons, e.g. the lack of information on tax payment containing data on income per month from informal sectors workers. Respondent, also, has an incentive to lie because it is difficult to verify the respondent's answers (Grosh, 1994). Therefore, many programs avoid using income as a poverty targeting method and using a method called PMT to construct a poverty scorecard instead.

PMT is a poverty targeting method using a small number of questions about household characteristics which helps limit the cost of collection: such as material used to make a roof of house or assets household currently own to estimate the probability that a household is poor via a statistical method (Kshirsagar, Wieczorek, Ramanathan, \& Wells, 2017; Paireepinas \& Grisanaputi, 2017; Purwanto \& Purba, 2017). These household characteristics will be used as a proxy of poverty where household characteristic will be used as independent variables in the regression model, while the dependent variable is either income, consumption or expenditure per capita. Then comes using a statistical method such as OLS to estimate the relationship between income and household characteristics. Then, it is about converting the estimated coefficient into a poverty score. After the construction of poverty scorecard, one must set a reasonable cutoff-score point to determine who would be eligible and who would not for the program. This is the general procedure of the PMT.

In Thailand, one of the CCT program launched by Ministry of Social Development and Human Security to subsidize newborn child (Child Support Grant) uses two criteria which consist of income and household status to determine poor household. The household which satisfies either of these conditions will be considered as poor. For income status, household income per month must not exceed 3,000 baht, and for household status, household of student must have at least one of the following conditions:

- Household burden condition: There is a disabled person or elder or unemployed with the age of 15-65 years or single parent in the household. This condition is grouped as:

- Housing quality: The living place is in a dilapidated condition or is made of local materials such as bamboo, leaves, etc., or living in rental housing or have no toilet in the area of living.

- Vehicle ownership condition: Having no car, small truck, pick-up truck, minivan, tractor, or har vester in household.

- Agricultural land ownership condition: Having no agricultural land or with less than 1 rai (equivalent to 1600 square meters) in the household.

Having adopted these criteria, Punyasavatsut (2017) targeted poor students in 10 provinces of Thailand, including Mae Hong Son, Nan, Nakhon Ratchasimi, Udon Thani, Nakhon Phanom, Chiang Rai, Trung, Kanchanaburi, Chanthaburi and Phuket through the PMT including household status condition from newborn child program as a proxy for poverty. However, they only included these conditions as a group, meaning that there are only 4 proxy variables, apart from province dummy variables, to be used in PMT poverty scorecard. This is where we can improve by including household characteristic variables separately from their group. This is where we can improve our study by separating these 4 groups into 12 household characteristic variables, which means that we will include more household characteristic variables into PMT poverty scorecard. We will also capture geographical characteristics by estimating each regression model separately in each province and create a PMT poverty scorecard for each province. 


\section{Research Objective}

This study aims to improve the efficiency of the PMT to be used as a tool for targeting poor students in Thailand by:

1) Including more household characteristic variables into PMT poverty scorecard.

2) Capturing geographical characteristics by estimating each model separately in each province and create a PMT poverty scorecard from estimation result for each province.

\section{Scope of the Study}

This study will be studied by using data on 10 provinces of Thailand, including Chiang Rai, Mae Hong Son, Kanchanaburi, Chanthaburi, Trang, Nakhon Phanom, Nakhon Ratchasima, Nan, Phuket and Udon ThaniMae Hong Son, Nan, Nakhon Ratchasimi, Udon Thani, Nakhon Phanom, Chiang Rai, Trung, Kanchanaburi, Chanthaburi and Phuket. Data to be used in this study is from Information System Development Project to Guarantee for Learning Opportunities. Punyasavatsut (2017) studied Thailand containing individual data on household income and household characteristic variables to be used as a proxy of poverty on 10 provinces of Thailand in 2017.

\section{REVIEW OF LITERATURE}

\section{Problem of Means Test}

Targeting the poor for social aids program has been a problem for some period of time because it is difficult to measure the actual welfare level of individual or household. One of the solutions to this problem is to use a true Means Test, which is based on income and wealth (Grosh, 1994). However, this solution is quite problematic as mention earlier in Chapter 1: Introduction. The empirical evaluation of Means Test used in food stamp programs in Sri Lanka and Jamaica is done in the studies by Edirisinghe (1987) and Grosh (1992), respectively. They found that these programs only delivered 57 and 56 percent of benefits to those in the poorest 40 percent of the population. This implied that a Means Test is not a good approach to determine the poor.

\section{$P M T$}

PMT was used as an alternative to combat this problem. In Haddad, Kennedy, and Sullivan (1994) studies, by having used household survey data from Brazil, Ghana, Mexico and Philippines, showed that some variables, which was easy to collect and validate, could be used as a good proxy for measures of caloric adequacy which was a standard measurement of the food and nutrition security. This is the same principle as a PMT using household characteristics other than income to predict their actual wealth.

Both studies by Glewwe, Kanaan, et al. (1989), in Cote d'Lvoire, and Grosh and Glinskaya (1997), in Armenia, proved that PMT was a good targeting indicator to be used as an approach to determine the poor. For a number of variables to be used as a poverty proxy, Grosh and Baker (1995) studied by using Living Standards Measurement Survey data in Jamaica, Bolivia and Peru, where they found that more information was preferred to less, although there were diminishing returns for more information added. This diminishing return also found in study by Bah, Bazzi, Sumarto, and Tobias (2018) where she found that out of 340 candidate variables, using a model random sampling method to select good predictions of household welfare in Indonesia, the best model to predict poverty in terms of undercoverage rate was the model with total 20 predicting variables. Also, Schreiner (2008a, 2009, 2010a, 2011, 2012a, 2016) developed a Poverty Probability Index (PPI) to be used as a poverty scorecard by using only 10 household characteristic variables to simplify the questionnaire and to reduce cost of data collecting. We can see from past studies that PMT has the potential to be used as a poverty targeting, and total number of household characteristic variables is around 10-20 variables is sufficient to construct PMT poverty scorecard. Next, we will discuss past studies on construction of PMT.

For the construction of PMT, resembles principle used in all studies, it is constructed through the use of regression model in order to obtain the relationship between (log of) expenditure or consumption per capita or poverty indicator variable and various household characteristic variables which are, usually, categorized into five groups:

- Household Demographics and Characteristics: Such as household size, the proportion of disabled person, proportion of old persons, proportion of child and age, sex, education level, type of the main job and marital status of household head, etc. 
- Housing Quality and Characteristics: Such as a dwelling, house ownership, house area, construction materials, number of rooms, kitchen, source of drinking water, cooking fuels and toilet facilities, etc.

- Household Ownership of Assets and Access to Facilities: Such as the ownership of a radio/stereo, television, $\mathrm{CD} / \mathrm{DVD} / \mathrm{video}$ player, refrigerator, telephone, computer, internet, bicycle, motorcycle, motor car, washing machine, vacuum cleaner, livestock, electricity and telephone bills, agricultural land, productive animals, etc.

- Economic Activities and Features: Such as type of occupation (permanent, temporary, agriculture, nonagriculture jobs, wage/unwaged worker), etc.

- Location where Household Lives: Such as urban or rural areas or other administrative division.

The coefficient of the estimation in each household characteristic variable gives the magnitude $f$ how much of that variable affects the consumption or expenditure. Usually, these coefficients will be multiplied by 100 and round to the nearest integer or transform into range between 0 and 1 or 0 and 100 for simplification.

For statistical method used to estimate this model, OLS was used in Ahmed and Bouis (2002); Bakhshoodeh (2013); Narayan and Yoshida (n.d.); Sharif (2009) study in Egypt, Sri Lanka, Bangladesh, and Iran, respectively. In term of efficiency of targeting the poor, Sharif (2009) comparing two poverty targeting, PMT and Community-based targeting. The simulated result from his model showed that PMT could improve the targeting efficiency comparing to the exist community-based targeting safety net programs. While Bakhshoodeh (2013) found that 70\% of poorest households will be targeted as poor if the cut-off point is set at percentile of per capita consumption of $40 \%$ which also results in highest accuracy in rural areas where poverty is much more severe than in urban area with leakage rate at just 7\%. Ahmed and Bouis (2002) found that their PMT score has 71.8 percent correctly targeting of the actual poor household and the rest (28.2 percent) are misidentified as non-poor when setting cut-off point at 149 , meaning that exclusion error is at 28.2 percent and inclusion error is 16.3 percent. This cut-off point reflects score in which household who just above the poverty line will be included as a poor.

Moreover, they also obtain the cut-off point at 217 where every poor household will be targeted as poor. As a result, error of inclusion in this scenario increases from 16.3 to 33.6 percent. Following Grosh and Baker (1995) evaluation of targeting accuracy approach, Narayan and Yoshida (n.d.) found that by setting cut-off point at 40 percentiles of actual per capita consumption, the leakage rate is at 44 percent, while the undercoverage rate is at 22 percent. And as cutoff-score point or percentiles decrease, say 30 percentiles, the leakage rate tends to go down, while the undercoverage rate tends to go up. These later two studies set a good example of the trade-off between inclusion and exclusion error in setting a cut-point. In addition to the use of OLS regression, a well-known poverty scorecard created by Schreiner (2008b, 2008a, 2009, 2010b, 2010a, 2011, 2011, 2012a, 2012c, 2012b, 2013, 2016), Poverty Probability Index (PPI), which is available for over 44 countries around the world, used Logistic regression as his main approach of estimation. The average total accuracy of his poverty scorecard from all of his work, around 44 countries, is approximately 70 percent.

We can see that other than OLS regression; another statistical method such as Logistic regression can be used to create a PMT poverty scorecard as well. The question is which methods are the best? To answer this question, Houssou et al. (2007) comparing PMT created in Uganda from various statistical estimation and compared result from each approach. These approaches are OLS, Linear Probability model, Probit, and Quantile regression estimation. They found that OLS and Probit regression performs better in predicting out-of-sample and more robust than others. They, also, suggested the use of OLS as its more convenient in creating a PMT poverty scorecard comparing to Probit regression.

\section{PMT in Thailand}

For past studied in Thailand, PMT has been developed by Punyasavatsut (2017) in order to target poor students in 10 provinces of Thailand, including Chiang Rai, Mae Hong Son, Kanchanaburi, Chanthaburi, Trang, Nakhon Phanom, Nakhon Ratchasima, Nan, Phuket, and Udon Thani. However, as mentioned earlier in Introduction, Punyasavatsut (2017) only included these conditions as a group, meaning that there were only 4 household characteristic variables i.e., household with elder and household with both elder and disabled person, for example, will have the same weight. To confirm that these household characteristic variables can be used as a good proxy of poverty, (Kambuya, 2017) studied, by using data from Thailand Social-Economic Survey (SES) in 2016, to find which household characteristic variables, in SES, could be used as a proxy for poverty. Of all methodologies used, Stepwise regression, Least Absolute 
Shrinkage, and Selection Operator (LASSO) and Random Forest, she found that most of variables in her models contain the set of variables as the same with the study of Punyasavatsut (2017) (Kambuya, 2017).

\section{RESEARCH METHODOLOGY}

The study by Punyasavatsut (2017) had provided us an individual data on household income and potential household characteristic variables on 10 provinces of Thailand in 2017 . We will randomly separate overall data into 2 sub-datasets by 70:30 ratio. That is, train (70\%) and test $(30 \%)$ dataset, where train dataset will be used in our estimation to create PMT poverty scorecard. Then, we will use this scorecard to targeting poor students in the test dataset.

For the number of actual poor and non-poor students, we determine them by using student's average monthly household income per capita and province poverty line as a criterion. We obtain a province poverty line of 2017 in Thailand from the National Economic and Social Development Board (NESDB) of Thailand. The poverty line of Thailand in 2017 is shown in Table 1:

Table 1 THAILAND'S 2017 POVERTY LINE (BAHT/PERSON/MONTH)

\begin{tabular}{ll}
\hline Province & Poverty Line \\
\hline & \\
Mae Hong Son & 2.320 \\
Nan & 2.331 \\
Nakhon Ratchasima & 2.364 \\
Udon Thani & 2.364 \\
Nakhon Phanom & 2.402 \\
Chiang Rai & 2.552 \\
Trung & 2.798 \\
Kanchanaburi & 2.801 \\
Chanthaburi & 2.980 \\
Phuket & 3.059 \\
\hline
\end{tabular}

The student whose average household income per month falls below the poverty line will be considered as actual poor and vice versa. This number of actual poor and non-poor students will be used later when we evaluate the performance of our PMT poverty targeting. For household characteristic variables, we can separate each category into the following variables:

1. There is a disabled person in the household.

2. There is an elder in the household.

3. There is an unemployment person with the age of 15-65 years in the household.

4. Student stays with a single parent.

5. Student living in rental housing.

6. The living place is in a dilapidated condition or is made of local materials such as bamboo, leaves, etc.

7. Having no toilet in the living area.

8. Having no personal car in the household.

9. Having no pick-up truck, small truck or minivan in household.

10. Having no tractor or harvester in the household.

11. Having agricultural land less than 1 rai (equivalent to 1600 square meters) in the household.

12. Having no agricultural land in the household. 
Therefore, we have 12 household characteristic variables to be used as a proxy for poverty where these variables should have a negative effect on average household income. That is, these household characteristic variables will be used as an independent variable for our regression model. Furthermore, we also include the following 3 independent variables as control variables, but we do not include in PMT poverty scorecard, as follows:

1. Number of a household member.

2. Years of household's head education.

3. Household's head is male.

But we do not include these 3 variables in PMT poverty scorecard as the number of household member and years of household head education are variables with numerical value. While, household head gender has small effect on household income and it is, sometimes, not clear whether who is a household head of the household in Thailand. While ( $\log$ off) average household income per month will be used as a dependent variable for our regression model. Now, we have train dataset, dependent and independent variables in our model. We will move on to the next topic, the statistical method used to estimate the model. In order to obtain the relationship between household characteristic variables and (log of) average household income per month, we must estimate the model we discussed above. The estimation technique to be used in our study is OLS regression. Let's define $\mathrm{N}, n_{\text {train }}$ and $n_{\text {test }}$ as a total number of observations in overall, train and test dataset where $N=n_{\text {train }}+n_{\text {train }}, \mathrm{X}$ as an $n_{\text {train }} \times k$ matrix of observations independent variables (Household characteristic variables) where $\mathrm{k}$ is a total number of independent variables, $\mathrm{B}$ as a $\mathrm{k} \times 1$ vector of unknown population parameters we want to estimate, $Y$ as an $n_{\text {train }} \times 1$ vector of observations on dependent variable (log of student's average monthly household income per capita) and $\varepsilon$ as an $n_{\text {train }} \times 1$ vector of errors term. The model can be written in matrix form as follows:

$$
Y=X B+\varepsilon
$$

The idea of OLS is to find parameters that minimize the Residual Sum of Squares (RSS) where RSS can be computed by:

$$
\begin{aligned}
S(B) & =\varepsilon^{2} \\
& =\left(Y-X^{\prime} B\right)^{2} \\
& =\left(Y-X^{\prime} B\right)^{\prime}\left(Y-X^{\prime} B\right) \\
S(B) & =Y^{\prime} Y-2 B^{\prime} X^{\prime} Y+B^{\prime} X^{\prime} X B
\end{aligned}
$$

Thus, OLS estimator for B can be obtained by solving:

$$
\hat{B}=\operatorname{argmin}_{B} S(B)
$$

By solving problem above using calculus, we can obtain estimated coefficient matrix as:

$$
\hat{B}=\left(X^{\prime} X\right)^{-1} X^{\prime} Y
$$

This $\hat{B}$ will serve as a matrix of the estimated coefficient for each $\mathrm{k}$ independent variable. These coefficients tell us a magnitude of the relationship between each household characteristic variable and (log of) average household income per month. This is the main concept of PMT. After we receive estimated coefficients, we will test each coefficient for its statistically significant by using individual T-test to test the following hypothesis:

$$
\begin{aligned}
\text { Null Hypothesis } & H_{0}: \beta_{j}=0 \\
\text { Alternate Hypothesis } & H_{1}: \beta_{j} \neq 0
\end{aligned}
$$

Where individual $t$-test can be computed as follows:

$$
t_{\hat{\beta}_{j}^{c a l}}=\frac{\hat{\beta}_{j}}{s e_{\hat{\beta}_{j}}} \sim t \frac{\alpha}{2}, \text { d.f. }=n_{\text {train }}-k
$$


Any coefficient that fails to reject the null hypothesis means that its coefficient is statistically insignificant at (1$\alpha) \times 100$ percent of confident level or indifference from zero. Which, also, means that any coefficient of household characteristic variable that is statistically insignificant has no statistically effect on household income. We will, also, regress each model separately by province (10 models overall) to capture any geographic characteristic in each province and create a unique scorecard for each province.

For PMT poverty scorecard, we will give each household characteristic in each province a PMT poverty score $\left(b_{j p}\right)$ by rescaling estimated coefficients in each province $\left(b_{j p}\right)$ to range between 0 and 100 by dividing each coefficient by the sum of coefficients in each province. Then, multiply this value by 100 and round to the nearest integer, that is:

$$
\check{b}_{j p}=\left[\frac{\hat{b}_{j p}}{\sum_{j=1}^{k} \hat{b}_{j p}} \times 100\right] \forall j=[1, k], p=[1,10] .
$$

Therefore, each student's household in test dataset will have their own unique PMT poverty score according to their household characteristic and province they inhabit in, that is:

$$
\text { pmtscore }_{i}=\sum_{j=1}^{k} x_{i j p} \breve{b}_{j p} \forall i=\left[1, n_{\text {test }}\right]
$$

This score will be a measurement of student poverty status from not poor to poorest in the test dataset, i.e. the higher the score, the poorer the student will be (100 is poorest) and vice versa.

For PMT poverty targeting, after we calculate a PMT poverty score for each student in the test dataset, we must set a cutoff-score point to determine which student will be targeted as poor and non-poor. For cutoff-score point, we will set cutoff-score at the point which student's average household income corresponds to province poverty line in Table 3 For evaluating the efficiency of poverty targeting, Grosh and Baker (1995) had provided a measurement for targeting error. There are 2 types of error in poverty targeting. These 2 types of error are Type-I or Exclusion error which occurs when a student is lypoor but has been targeted as a non-poor and Type-II or Inclusion error occurs when student is actual non-poor but have been targeted as a poor. To measure these errors, Grosh and Baker (1995) computed a Leakage and Undercoverage rate by:

- Leakage rate: Calculated by dividing a total number of actual non-poor households who have been incorrectly targeted as a poor household (Type-II inclusion error) with a total number of actually poor households.

- Undercoverage rate: Calculated by dividing a total number of actual poor households who have been incorrectly targeted as a non-poor household (Type-I exclusion error) with a total number of actually poor households.

Furthermore, there are another two targeting accuracy rates which are, also, used to measure the performance of the model suggested by IRIS (2005) as follows:

- Poverty accuracy rate: Calculated by dividing a total number of actual poor households who have been correctly targeted as a poor household and a total number of actually poor households.

- Total accuracy rate: Calculated by dividing the total number of correctly targeted households and a total number of households. 
These four measurements can be summarized as the following Table 2:

Table 2 TARGETING PERFORMANCE CALCULATION

\begin{tabular}{|c|c|c|c|c|c|}
\hline & \multicolumn{2}{|c|}{ Actual Poor } & \multicolumn{2}{|l|}{ Actual Non-Poor } & Total \\
\hline $\begin{array}{l}\text { Targeted as Poor } \\
\text { Targeted as Non-Poor } \\
\text { Total }\end{array}$ & $\begin{array}{l}\text { Correctl } \\
\text { Type-I e } \\
\left(N_{1}\right)\end{array}$ & is poor $\left(T_{1}\right)$ & \multicolumn{2}{|c|}{$\begin{array}{l}\text { Correctly targeted as non-poor }\left(T_{2}\right) \\
\left(\mathrm{N}_{2}\right)\end{array}$} & $\begin{array}{l}\left(P_{1}\right) \\
\left(P_{2}\right) \\
(\mathrm{N})\end{array}$ \\
\hline $\begin{array}{l}\text { where: } \\
\text { Leakage rate }=E_{2} / N_{1} \\
\text { Undercoverage rate }= \\
\text { Poverty accuracy rate } \\
\text { Total accuracy rate }=( \\
\text { Source: Summarized b }\end{array}$ & based on & & & & \\
\hline \multicolumn{6}{|c|}{$\begin{array}{l}\text { We will use these } 4 \text { measurements to evaluate the performance of PMT targeting in each cutoff-score point in th } \\
\text { dataset. That is, we try to evaluate the out-of-sample targeting of PMT poverty score which is created from trair } \\
\text { set. }\end{array}$} \\
\hline \multicolumn{6}{|c|}{ RESULTS AND DISCUSSION } \\
\hline \multicolumn{6}{|c|}{$\begin{array}{l}\text { After we received data, we cleaned out any error and outlier data. Having cleaned data, we had overall } 388,85 \\
\text { students left in our data sample where we had the only student whose average household income per month was in the } \\
\text { range between } 100 \text { to } 20,000 \text { baht per month. We, then, split our data into } 2 \text { sub-datasets: train and test. Where we } \\
\text { had total of } 272,343 \text { students in train dataset and total of } 116,508 \text { students in test dataset. For descriptive statistics } \\
\text { firstly, we would separate the actual poor and non-poor students in overall dataset by using student's average monthly } \\
\text { household income per capita and province poverty line as shown in Table } 1 \text {. Total number and proportion of actua } \\
\text { poor and non-poor students in each province are shown in Table } 3 \text { below: }\end{array}$} \\
\hline \multirow{2}{*}{ Province } & \multicolumn{2}{|c|}{ Actual Poor Students } & \multicolumn{3}{|c|}{ Actual Non-poor Students } \\
\hline & Total & Proportion & Total & Prop & ortion \\
\hline Mae Hong Son & 10,915 & $83.06 \%$ & 2,226 & 16.9 & $4 \%$ \\
\hline Nan & 13,685 & $71.94 \%$ & 5,338 & 28.0 & \\
\hline Nakhon Ratchasima & 68,526 & $61.62 \%$ & 42,686 & 38.3 & \\
\hline Udon Thani & 44,315 & $67.12 \%$ & 21,708 & 32.8 & \\
\hline Nakhon Phanom & 41,183 & $75.11 \%$ & 13,650 & 24.8 & $9 \%$ \\
\hline Chiang Rai & 37,852 & $76.10 \%$ & 11,885 & 23.9 & \\
\hline Trung & 9,176 & $78.27 \%$ & 2,547 & 21.7 & \\
\hline Kanchanaburi & 30,063 & $71.82 \%$ & 11,798 & 28.1 & \\
\hline Chanthaburi & 10,633 & $66.33 \%$ & 5,398 & 33.6 & \\
\hline Phuket & 2,439 & $46.31 \%$ & 2,828 & 53.6 & $9 \%$ \\
\hline Total & 268,787 & $69.12 \%$ & 120,064 & 30.8 & \\
\hline
\end{tabular}

Source: Author's calculation based on Punyasavatsut (2017) dataset

From Table 3, we found that most of 10 provinces in Thailand have actual poor students more than non-poor except in Phuket which has actual non-poor students more than poor students, which, also, has the lowest proportion of 
poor students at around 46 percent. Also, we found that Mae Hong Son province has the highest proportion of poor students at around 83 percent following with Trung, Chiang Rai and Nakhon Phanom with proportion of poor students at around 78, 76 and 75 percent, respectively. Next, we would explore proportion of household characteristics in Table 4:

Table 4 PROPORTION OF STUDENT WITH 12 HOUSEHOLD CHARACTERISTICS IN 10 PROVINCES OF THAILAND

Household Characteristics

There is a disabled person in the household.

There is an elder in the household.

There is an unemployment person with the age of 15-65 years in the household.

Student stays with a single parent.

Student living in rental housing.

The living place is in a dilapidated condition or is made of local materials such as bamboo, leaves, etc.

Having no toilet in the living area.

Having no personal car in the household.

Having no pick-up truck, small truck, or a minivan in household.

There is a tractor or harvester in the household.

Having agricultural land less than 1 rai (equivalent to 1600 square meters) in the household.

Having no agricultural land in the household.
Proportion to Overall Students

$5.72 \%$

$28.46 \%$

$27.27 \%$

$18.69 \%$

$7.22 \%$

$35.20 \%$

$2.34 \%$

$86.86 \%$

$88.66 \%$

$88.67 \%$

$20.39 \%$

$31.65 \%$

Source: Author's summarization based on Punyasavatsut (2017) dataset.

From Table 4, we found that about 6 percent of overall student have a disabled person in the household, about 28 percent have an elder in household, about 27 percent have an unemployment person with age of 15-65 years in household and about 19 percent staying with single parent. Very few livings in rental house with proportion around 7 percent. Also, only 2 percent of student have no toilet in living area. While, 35 percent living place is a dilapidated house or being made of local material. For vehicles ownership, we found that most of student have no vehicles in household (about $87 \%$ in both person car, pick-up truck, small truck, minivan, tractor or harvester.) For agricultural land, about 20 percent have land less than 1 rai (1,600 square meters), and 31 percent have no agricultural land. Next, we will further our investigation by exploring proportion of household characteristics between actual poor and non-poor students in Table 5:

Table 5 PROPORTION OF HOUSEHOLD CHARACTERISTICS BETWEEN ACTUAL POOR AND NON-POOR STUDENTS IN 10 PROVINCES OF THAILAND

Household Characteristics

There is a disabled person in the household.

There is an elder in the household.

There is an unemployment person with the age of 15-65 years in the household.

Student stays with single parent

Student living in rental housing.

The living place is in a dilapidated condition or is made of local materials such as bamboo, leaves, etc.

Having no toilet in the living area.
Proportion to Proportion to

Actual Poor Actual Non-Poor

$6.47 \% \quad 4.03 \%$

$30.41 \% \quad 24.09 \%$

$30.45 \% \quad 20.15 \%$

$19.23 \% \quad 17.47 \%$

$6.17 \% \quad 9.57 \%$

$41.62 \% \quad 20.82 \%$

$2.94 \% \quad 1.02 \%$ 
Table 5 CONTINUED

$\begin{array}{lll}\text { Having no personal car in the household. } & 91.74 \% & 75.94 \% \\ \text { Having no pick-up truck, small truck, or a minivan in household. } & 92.49 \% & 80.07 \% \\ \begin{array}{l}\text { There is a tractor or harvester in the household. } \\ \text { Having agricultural land less than 1 rai (equivalent to 1600 square meters) }\end{array} & 89.65 \% & 86.49 \% \\ \begin{array}{l}\text { in the household. } \\ \text { Having no agricultural land in the household. }\end{array} & 34.26 \% & 25.79 \%\end{array}$

Source: Author's summarization based on Punyasavatsut (2017) dataset.

Table 5 suggested us that most of the household characteristic we included in PMT poverty scorecard could be served as a good proxy of poverty since actual poor students tend to have higher proportion in every household characteristic except for living in a rental house which has higher proportion in actual non-poor than to actual poor students at around 3 percent. This is just descriptive statistics, however. To answer whether these household characters are serving as a good proxy of poverty or not, we have to continue to our regression estimation.

Estimated coefficients from each model will tell us the magnitude and direction of the relationship between household's characteristic variable and (log of) student's average monthly household income per capita (See regression result from Stata in Appendix B). By using train dataset in OLS regression, estimated coefficients from each province are as shown in the following Table 6:

Table 6 MEAN OF YEARS OF HOUSEHOLD'S HEAD EDUCATION OF EACH HOUSEHOLD CHARACTERISTICS IN 10 PROVINCES OF THAILNAD

\begin{tabular}{|c|c|c|c|c|c|}
\hline \multirow{2}{*}{$\begin{array}{l}\text { Household Characteristic } \\
\text { Variables }\end{array}$} & \multicolumn{5}{|c|}{ Province } \\
\hline & $\begin{array}{l}\text { Mae Hong } \\
\text { Son }\end{array}$ & Nan & $\begin{array}{l}\text { Nakhon } \\
\text { Ratchasima }\end{array}$ & Udon Thnai & $\begin{array}{l}\text { Nakhon } \\
\text { Phanom }\end{array}$ \\
\hline $\begin{array}{l}\text { There is a disabled person in house- } \\
\text { hold. }\end{array}$ & 0.0029 & -0.042 & $-0.1135 * * *$ & $-0.1426 * * *$ & $-0.0953 * * *$ \\
\hline There is an elder in household. & 0.0409 & $-0.039 * *$ & $-0.2088 * * *$ & $-0.1885^{* * *}$ & $-0.126 * * *$ \\
\hline $\begin{array}{l}\text { There is an unemployment person with } \\
\text { the age of } 15-65 \text { years in household. }\end{array}$ & $-0.111 * * *$ & $-0.147 * * *$ & $-0.1613 * * *$ & $-0.2052 * * *$ & $-0.1799 * * *$ \\
\hline Student stays with single parent. & $-0.104 * * *$ & -0.031 & 0.0048 & -0.0019 & -0.0152 \\
\hline Student living in rental housing. & $0.196 * * *$ & $0.222 * * *$ & $0.1237 * * *$ & $0.0868 * * *$ & $0.095^{* * *}$ \\
\hline $\begin{array}{l}\text { The living place is in dilapidated con- } \\
\text { dition or is made of local materials } \\
\text { such as bamboo, leaves, etc. }\end{array}$ & $-0.362 * * *$ & $-0.277 * * *$ & $-0.2152 * * *$ & $-0.219 * * *$ & $-0.2296 * * *$ \\
\hline Having no toilet in the living area. & $-0.325 * * *$ & $-0.3003 * * *$ & $-0.0519 * * *$ & $-0.1108 * * *$ & $-0.1171 * * *$ \\
\hline Having no personal car in household. & $-0.743 * * *$ & $-0.512 * * *$ & $-0.4323 * * *$ & $-0.4026 * * *$ & $-0.508 * * *$ \\
\hline $\begin{array}{l}\text { Having no pick-up truck, small truck } \\
\text { or minivan in household. }\end{array}$ & $-0.348 * * *$ & $-0.323 * * *$ & $-0.3578 * * *$ & $-0.3769 * * *$ & $-0.4631 * * *$ \\
\hline $\begin{array}{l}\text { Having no tractor or harvester in } \\
\text { household. }\end{array}$ & $-0.223 * * *$ & -0.040 & $-0.0513 * * *$ & $-0.04 * * *$ & $-0.0431 * * *$ \\
\hline $\begin{array}{l}\text { Having agricultural land less than } 1 \text { rai } \\
\text { (equivalent to } 1600 \text { square meters). }\end{array}$ & $-0.136 * * *$ & $-0.117 * * *$ & $-0.0644 * * *$ & $-0.0622 * * *$ & $-0.0873 * * *$ \\
\hline $\begin{array}{l}\text { Having no agricultural land in house- } \\
\text { hold. }\end{array}$ & $-0.175 * * *$ & $-0.157 * * *$ & $-0.0536 * * *$ & $-0.1018 * * *$ & $-0.0749 * * *$ \\
\hline Constant term & $8.749 * * *$ & $8.167 * * *$ & $8.2647 * * *$ & $8.1955 * * *$ & $8.2251 * * *$ \\
\hline R-square & 0.36 & 0.197 & 0.1769 & 0.1606 & 0.1487 \\
\hline Number of Observation & 9,159 & 13,285 & 78,094 & 46,322 & 38,331 \\
\hline
\end{tabular}


Table 6 CONTINUED FOR REMAINING 5 PROVINCES

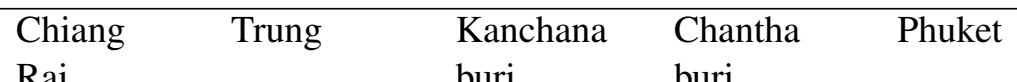

Rai buri buri hold.

There is an elder in household.

$-0.0665 * * * \quad-0.0554 * *$

$-0.1119 * * *$

$-0.0719 * * *$

$-0.2191 * * *$

There is an unemployment person with

$-0.0321 * * *$

$-0.084 * * *$

$-0.0893 * * *$

$-0.12 * * *$

$-0.0206$

the age of 15-65 years in household.

Student stays with single parent.

$-0.1441 * * *$

$-0.163 * * *$

$-0.1039 * * *$

$-0.1815 * * *$

$-0.1349 * * *$

Student living in rental housing.

$-0.0394 * * *$

0.0023

$-0.0071$

$-0.042 * * *$

$-0.0331$

The living place is in dilapidated con-

$0.0284 * *$

$0.0507 * *$

$0.105 * * *$

$0.0913 * * *$

$0.0786 * * *$

dition or is made of local materials

$-0.2337 * * *$

$-0.150 * * *$

$-0.1922 * * *$

$-0.199 * * *$

$-0.1893 * * *$

such as bamboo, leaves, etc.

Having no toilet in the living area.

$-0.1707 * * *$

$-0.279 * * *$

$-0.1823 * * *$

$-0.2496 * * *$

$-0.1006$

Having no personal car in household.

$-0.4102 * * *$

$-0.416^{* * *}$

$-0.404 * * *$

$-0.3347 * * *$

$-0.3285 * * *$

Having no pick-up truck, small truck

$-0.33 * * *$

$-0.333 * * *$

$-0.3296 * * *$

$-0.3086^{* * * *}$

$-0.3404 * * *$

or minivan in household.

Having no tractor or harvester in

$-0.0451 * * * \quad-0.0006$

$-0.0552 * * *$

$-0.0628^{* *}$

$-0.0462$

household

Having agricultural land less than 1 rai

$-0.066 * * *$

$-0.098^{* * *}$

$-0.07 * * *$

$-0.0997 * * *$

$-0.0994 * * *$ (equivalent to 1600 square meters).

Having no agricultural land in household.

Constant term

$-0.1002 * * *$

$-0.198 * * *$

$-0.0765 * * *$

$-0.1007 * * *$

$-0.1315 * * *$

R-square

$8.3774 * * *$

$8.4484 * * *$

$8.4318^{* * *}$

$8.5504 * * *$

$9.039 * * *$

Number of Observation

$0.1934 \quad 0.171$

0.1817

0.1817

0.2222

34,710

8,196

29,348

11,257

3,641

* is statistically significant at 0.10 significant level which is corresponding to $90 \%$ of confidence level.

$* *$ is statistically significant at 0.05 significant level which is corresponding to $95 \%$ of confidence level.

$* * *$ is statistically significant at 0.01 significant level which is corresponding to $99 \%$ of confidence level.

Source: Author's calculation in Stata based on Punyasavatsut (2017) dataset.

From estimated household characteristic coefficients, we found an anomaly in the household living in rental housing. In practice, if we are to compare student living in a rental house and their own house, living in a rental house should have a negative effect on household income. That is, they should be poorer than household who owns a house. Our regression result; however, suggests another way around, i.e. living in rental housing has a positive effect on household income and is statistically significant. This result is the same as suggested by descriptive statistics; the proportion of actual non-poor students who live in rental house is higher than household who is actually poor.

Moreover, student living in rental house has higher mean of average household income per month than student who does not live in rental house (see Table 9) Another explanation to this problem is that we do not have data on whether student who does not live in rental house owning a house or living in others house such as their relatives. Therefore, we will exclude living in rental housing variable in creating PMT poverty scorecard.

For statistically significant in estimated coefficient, we found that most of the household's characteristic variables are statistically significant in most of all provinces, except for one variable: Student stays with single parent variable. Of all 10 provinces, this variable only statistically significant in Chanthaburi, Chiang Rai and Mae Hong Son. This may due to the fact that student who stays with either single mother or father does not always mean that parent, who does not stay with student now, will leave him/her without any alimony after divorce. We also test for robustness by using robust standard errors instead of normal standard errors. Results are indifference in both normal and robust standard errors.

After we had estimated the relation between household's characteristic variables and (log of) student's average monthly household income per capita, we would convert our estimated coefficient into PMT poverty score which lies 
between 0 and 100. There are 2 things we needed to concern in our PMT poverty scorecard. First, as we explained in the previous section, we would exclude living in rental housing variable from PMT poverty scorecard. Therefore, we had only 11 household characteristic variables left. Another concern was that, as household characteristic variables should have a negative effect on household income, any estimated coefficient from Table 4 that has positive effect on income would receive 0 in our PMT poverty scorecard. The PMT poverty scorecard for each province are shown in the following Table 7:

Table 7 PROPORTION OF HOUSEHOLD CHARACTERISTICS BETWEEN ACTUAL POOR AND NON-POOR STUDENTS IN 10 PROVINCES OF THAILAND

Household Characteris-

Province

tic

Variables

Son sima

There is a disabled per- 0
son in the household.

There is an elder in the

household.

There is an unemploy-
ment person with the

age of 15-65 years in

the household.

Student stays with sin-

gle parent.

The living place is in

$\begin{array}{llll}14 & 14 & 13 & 12\end{array}$

8

5

4

3

7

4

13

a dilapidated condition

or is made of local ma-

terials such as bamboo,

leaves, etc.

Having no toilet in the

living area.

Having no personal car

in the household.

Having no pick-up

truck, small truck, or a

$13 \quad 15 \quad 3$

10

6

25

6

7

1

$\begin{array}{lll}4 & 7 & 9\end{array}$

11

9

9

9

7

10

8

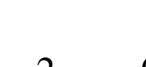

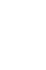

\section{minivan in household.}

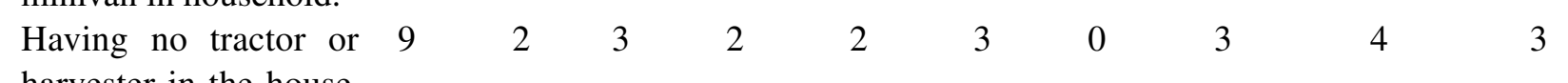

harvester in the house-

hold.

$\begin{aligned} & \text { Having agricultural } \\ & \text { land less than } 1 \text { rai } \\ & \text { (equivalent to } 1600\end{aligned}$
$\begin{aligned} & \text { square meters) in the } \\ & \text { household. }\end{aligned}$


As we stated earlier, variables which have 0 PMT poverty score in PMT poverty scorecard (Table 4) are as follows:

- There is a disabled person in the household variable in Mae Hong Son.

- There is an elder in the household variable in Mae Hong Son.

- Student stays with single parent variable in Kanchanaburi, Nakhon Ratchasima, Trung, and Udon Thani.

- Having no tractor in the household variable in Trung.

There are 2 explanations for these problem variables, an average household income, and a household's head education. Firstly, is by the fact that mean of student's average monthly household income per capita in these groups is almost the same as those group of students without these characteristics in these provinces above (See Table 8) Secondly, mean of years of household's head education in above group is higher than group of students without these characteristics in these provinces above (See Table 9) The higher years of education means the higher chances of household to involve in a job which gives higher payroll. These are reasons why these 4 household characteristic variables have positive effect on income in these provinces from above.

From PMT poverty scorecard in Table 7, variable which has the most effect on poverty in 10 provinces of Thailand (highest score in most of all province) is when student's household does not own a personal car. While the least (lowest score in most of all province) is when student staying with a single parent. This is the same result as suggested by individual $t$-test in Table 6. Moreover, we found that some variables have a huge difference in PMT poverty score between each province. These variables are the following:

- Having a disability in the household variable which has a very low PMT poverty score in Mae Hong Son (0) and Nan (2,) while it is quite high in Phuket (13).

- Having no toilet in the household variable which has a low PMT poverty score in Nakhon Ratchasima (3,) Udon Thani (6,) Nakhon Phanom (6,) and Phuket (6) comparing to other provinces.

- Having no tractor in the household variable, which has a high PMT poverty score in Mae Hong Son (9) comparing to other provinces.

- Having no agriculture land in the household variable, which has a low PMT poverty score in Nakhon Ratchasima (3) and Nakhon Phanom (4) comparing to other provinces.

This suggested to us that there is exists of geographical difference between each province in some household characteristic variables as some variable has a high PMT poverty score in some province, while it is not in other provinces and vice versa. Using the same set of household characteristic variables in all province may not be an effective way of PMT poverty targeting.

Table 8 MEAN OF YEARS OF HOUSEHOLD'S HEAD EDUCATION OF EACH HOUSEHOLD CHARACTERISTICS IN 10 PROVINCES OF THAILNAD

\begin{tabular}{|c|c|c|c|c|}
\hline \multirow[t]{2}{*}{ Household Characteristic Variables } & \multicolumn{4}{|c|}{ Province } \\
\hline & $\begin{array}{l}\text { Mae Hong Nan } \\
\text { Son }\end{array}$ & $\begin{array}{l}\text { Nakhon } \\
\text { Ratchasima }\end{array}$ & Udon Thnai & $\begin{array}{l}\text { Nakhon } \\
\text { Phanom }\end{array}$ \\
\hline
\end{tabular}

There is a disabled person in household.

No

Yes

There is an elder in household.

No

Yes

$1,694.21$

$1,559.12$

$1,371.49$

$2,065.03$

$1,628.01$

$2,442.43$

$1,896.56$

$2,264.72$

$1,739.36$

$1,944.79$

$1,535.21$

$2,100.12 \quad 2,569.82$

$1,888.40 \quad 2,063.89$

$2,386.87$

$1,911.26$

$2,014.78$

$1,703.33$

There is an unemployment person with the age of 15-65 years in household.

$\begin{array}{llllll}\text { No } & 1,715.98 & 2,157.12 & 2,571.86 & 2,445.80 & 2,065.54 \\ \text { Yes } & 1,046.87 & 1,640.59 & 1,985.50 & 1,793.71 & 1,583.43\end{array}$


Table 8 CONTINUED..

\begin{tabular}{|c|c|c|c|c|c|}
\hline \multicolumn{6}{|c|}{ Student stays with single parent. } \\
\hline No & $1,627.92$ & $2,059.79$ & $2,433.19$ & $2,266.65$ & $1,941.71$ \\
\hline Yes & $1,278.13$ & $1,909.64$ & $2,311.41$ & $2,061.79$ & $1,824.35$ \\
\hline \multicolumn{6}{|c|}{ Student living in rental housing. } \\
\hline No & $1,526.96$ & $2,018.76$ & $2,381.47$ & $2,226.16$ & $1,914.57$ \\
\hline Yes & $2,693.97$ & $2,684.58$ & $2,765.37$ & $2,387.54$ & $2,342.80$ \\
\hline \multicolumn{6}{|c|}{ The living place is in dilapidated condition or is made of local materials such as bamboo, leaves, etc. } \\
\hline No & $2,649.80$ & $2,329.18$ & $2,762.30$ & $2,505.40$ & $2,111.85$ \\
\hline Yes & 947.67 & $1,294.52$ & $1,853.42$ & $1,583.22$ & $1,377.67$ \\
\hline \multicolumn{6}{|c|}{ Having no toilet in the living area. } \\
\hline No & $1,631.69$ & $2,062.95$ & $2,420.19$ & $2,244.58$ & $1,930.99$ \\
\hline Yes & 737.08 & 983.197 & $1,861.74$ & $1,539.26$ & $1,288.37$ \\
\hline \multicolumn{6}{|c|}{ There is no personal car in household. } \\
\hline No & $4,431.79$ & $3,392.62$ & $4,002.23$ & $3,662.94$ & $3,385.39$ \\
\hline Yes & $1,193.03$ & $1,758.91$ & $2,213.52$ & $2,023.24$ & $1,716.75$ \\
\hline \multicolumn{6}{|c|}{ There is no Pick-up truck, small truck or minivan in household } \\
\hline No & $3,350.12$ & $2,820.20$ & $3,691.03$ & $3,556.03$ & $3,210.71$ \\
\hline Yes & $1,453.59$ & $1,857.27$ & $2,240.40$ & $2,035.81$ & $1,782.55$ \\
\hline \multicolumn{6}{|c|}{ There is no tractor or harvester in household. } \\
\hline No & $2,430.09$ & $2,500.38$ & $2,901.70$ & $2,560.49$ & $2,082.39$ \\
\hline Yes & $1,528.49$ & $1,993.80$ & $2,361.87$ & $2,149.75$ & $1,876.23$ \\
\hline \multicolumn{6}{|c|}{ Having agricultural land less than 1 rai (equivalent to 1600 square meters) in household. } \\
\hline No & $1,677.83$ & $2,151.03$ & $2,466.18$ & $2,305.57$ & $1,992.73$ \\
\hline Yes & $1,323.50$ & $1,779.24$ & $2,155.22$ & $1,926.91$ & $1,635.52$ \\
\hline \multicolumn{6}{|c|}{ Having no agricultural land in household. } \\
\hline No & $1,932.05$ & $2,179.30$ & $2,538.41$ & $2,370.34$ & $1,962.88$ \\
\hline Yes & $1,055.10$ & $1,652.51$ & $2,147.69$ & $1,806.77$ & $1,661.70$ \\
\hline
\end{tabular}

Table 8 CONTINUED FOR REMAINING 5 PROVINCES

$\begin{array}{llll}\begin{array}{l}\text { Chiang } \\ \text { Rai }\end{array} & \text { Trung } & \begin{array}{l}\text { Kanchana } \\ \text { buri }\end{array} & \begin{array}{l}\text { Chantha } \\ \text { buri }\end{array}\end{array}$ Phuket

There is a disabled person in household.

$\begin{array}{lrrrrr}\text { No } & 2,055.78 & 2,117.63 & 2,389.01 & 2,737.09 & 3,833.50 \\ \text { Yes } & 1,811.14 & 1,679.36 & 1,927.73 & 2,351.82 & 2,746.49 \\ \text { There is an elder in household. } & & & & \\ \text { No } & 2,059.23 & 2,174.35 & 2,422.96 & 2,790.01 & 3,885.92 \\ \text { Yes } & 1,994.81 & 1,825.84 & 2,194.38 & 2,480.72 & 3,215.65 \\ \text { There is an unemployment person with the age of } 15-65 \text { years in household. } & & \\ \text { No } & 2,158.06 & 2,225.66 & 2,486.36 & 2,856.43 & 4,017.43 \\ \text { Yes } & 1,674.21 & 1,612.60 & 2,011.19 & 2,238.46 & 2,985.22 \\ \text { Student stays with single parent. } & & & & \\ \text { No } & 2,080.47 & 2,113.51 & 2,380.26 & 2,734.63 & 3,830.86 \\ \text { Yes } & 1,900.36 & 1,988.79 & 2,322.97 & 2,619.86 & 3,669.56 \\ \text { Student living in rental housing } & & & & & \\ \text { No } & 2,040.14 & 2,093.53 & 2,346.78 & 2,686.60 & 3,601.69 \\ \text { Yes } & 2,071.26 & 2,075.64 & 2,549.78 & 2,812.14 & 3,963.86\end{array}$


Table 8 CONTINUED..

The living place is in dilapidated condition or is made of local materials such as bamboo, leaves, etc.

$\begin{array}{lrrrrr}\text { No } & 2,417.13 & 2,279.46 & 2,720.19 & 2,996.72 & 4,039.21 \\ \text { Yes } & 1,467.41 & 1,573.54 & 1,873.11 & 2,088.44 & 2,789.26 \\ \text { Having no toilet in the living area. } & & & & & \\ \text { No } & 2,065.42 & 2,122.05 & 2,390.73 & 2,734.96 & 3,810.93 \\ \text { Yes } & 1,265.62 & 1,364.73 & 1,605.52 & 1,765.64 & 2,559.63 \\ \text { There is no personal car in household. } & & & & & \\ \text { No } & 3,534.09 & 3,204.86 & 3,570.38 & 3,775.327 & 5,085.00 \\ \text { Yes } & 1,803.74 & 1,893.24 & 2,142.05 & 2,484.06 & 3,510.80\end{array}$

There is no Pick-up truck, small truck or minivan in household.

$\begin{array}{lrrrrr}\text { No } & 3,198.56 & 3,362.32 & 3,443.82 & 3,763.37 & 4,977.34 \\ \text { Yes } & 1,884.65 & 2,048.23 & 2,243.26 & 2,556.15 & 3,741.24 \\ \text { There is no tractor or harvester in household. } & & & & \\ \text { No } & 2,598.63 & 2,051.52 & 2,925.66 & 2,918.16 & 4,013.79 \\ \text { Yes } & 1,999.20 & 2,093.36 & 2,343.72 & 2,701.10 & 3,784.59\end{array}$

Having agricultural land less than 1 rai (equivalent to 1600 square meters) in household.

\begin{tabular}{llrrrr} 
No & $2,095.84$ & $2,135.63$ & $2,382.03$ & $2,778.07$ & $3,809.35$ \\
Yes & $1,851.69$ & $1,934.15$ & $2,314.09$ & $2,437.43$ & $3,603.27$ \\
Having no agricultural land in household. & & & & \\
No & $2,300.61$ & $2,317.59$ & $2,572.09$ & $2,901.88$ & $4,175.82$ \\
Yes & $1,692.21$ & $1,705.83$ & $2,079.56$ & $2,416.52$ & $3,506.65$ \\
\hline
\end{tabular}

Table 9 MEAN OF YEARS OF HOUSEHOLD'S HEAD EDUCATION OF EACH HOUSEHOLD CHARACTERISTICS IN 10 PROVINCES OF THAILNAD

\begin{tabular}{lllll}
\hline Mae Hong & Nan & Nakhon & Udon Thani & Nakhon \\
Son & Nan & Ratchasima & Udon Thani & Phanom \\
\hline
\end{tabular}

There is a disabled person in household.

No

3.86

6.73

6.53

6.26

6.28

Yes

4.09

$6.38 \quad 5.92$

5.95

5.96

There is an elder in household.

No

3.70

6.69

6.70

6.39

6.4

Yes

5.13

6.75

6.06

5.94

5.94

There is an unemployment person with the age of 15-65 years in household.

$\begin{array}{llllll}\text { No } & 4.18 & 6.82 & 6.61 & 6.35 & 6.34 \\ \text { Yes } & 2.91 & 6.37 & 6.21 & 6.04 & 6.07 \\ \text { Student stays with single parent. } & & & & & \\ \text { No } & 3.88 & 6.66 & 6.45 & 6.23 & 6.22 \\ \text { Yes } & 3.82 & 6.95 & 6.68 & 6.307 & 6.44 \\ \text { Student living in rental housing. } & & & & & \\ \text { No } & 3.82 & 6.68 & 6.42 & 6.22 & 6.24 \\ \text { Yes } & 5.93 & 8.14 & 7.41 & 6.82 & 7.45\end{array}$

The living place is in dilapidated condition or is made of local materials such as bamboo, leaves, etc.

$\begin{array}{llllll}\text { No } & 5.64 & 7.19 & 6.84 & 6.42 & 6.42 \\ \text { Yes } & 2.89 & 5.51 & 5.95 & 5.82 & 5.79\end{array}$


Having no toilet in the living area.

No

Yes

There is no personal car in household.

No

Yes

There is no Pick-up truck, small truck or minivan in household

No

Yes

There is no tractor or harvester in household.

No

Yes
4.09

1.57

6.77

4.60

6.51

6.00

$8.59 \quad 7.85$

$6.33 \quad 6.33$

6.56

3.72

8.04

7.56

6.36

7.25

6.73

$6.66 \quad 6.47$

4.76

3.84
6.26

5.50

6.27

5.66

Having agricultural land less than 1 rai (equivalent to 1600 square meters) in household.

No

Yes

3.99

3.64

6.85

6.56

$6.40 \quad 6.20$

$6.93 \quad 6.57$

$6.13 \quad 6.36$

4.52

3.02

No

Yes

Table 9 CONTINUED FOR REMIANING 5 PROVINCES

7.23

7.52

6.10

6.08

7.17

7.23

6.11

6.15
6.33

6.25

6.22

6.26
6.27

$6.04 \quad 6.19$

$6.32 \quad 6.25$

6.02

6.34

\begin{tabular}{lllll}
$\begin{array}{l}\text { Chiang } \\
\text { Rai }\end{array}$ & Trung & $\begin{array}{l}\text { Kanchana } \\
\text { buri }\end{array}$ & $\begin{array}{l}\text { Chantha } \\
\text { buri }\end{array}$ & Phuket \\
\hline
\end{tabular}

There is a disabled person in household.

No

Yes

There is an elder in household.

No

Yes

4.74

5.05

7.09

5.36

$6.71 \quad 5.32$

4.60

5.20

7.12

5.31

$6.91 \quad 5.54$

d.

No

Yes

4.82

4.54

7.19

5.42

6.63

5.17

4.69

5.01

4.74

4.98

$\begin{array}{ll}7.01 & 5.27\end{array}$

5.27
5.73

$7.36 \quad 5.73$

No

Student living in rental housing.

No

Yes

7.05

5.39

5.11

The living place is in dilapidated condition or is made of local materials such as bamboo, leaves, etc.

No

Yes

Having no toilet in the living area.

No

Yes

There is no personal car in household.

No

Yes $\begin{array}{lll}5.48 & 7.23 & 5.93\end{array}$

3.65

6.63

4.57

7.12

5.41

$5.85 \quad 3.66$

2.71

7.09

4.38

7.98

6.99

$6.91 \quad 5.05$

5.05

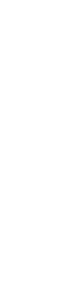


Table 9 CONTINUED.

There is no Pick-up truck, small truck or minivan in household.

\begin{tabular}{lccccc} 
No & 6.63 & 7.99 & 6.84 & 6.91 & 7.99 \\
Yes & 4.50 & 7.04 & 5.19 & 5.96 & 7.71 \\
There is no tractor or harvester in household. & & & & & \\
No & 5.88 & 7.22 & 6.28 & 6.36 & 7.25 \\
Yes & 4.67 & 7.06 & 5.32 & 6.07 & 7.73 \\
Having agricultural land less than 1 rai (equivalent to 1600 & square meters) & in household. & \\
No & 4.83 & 7.14 & 5.33 & 6.08 & 7.72 \\
Yes & 4.48 & 6.81 & 5.50 & 6.11 & 7.70 \\
Having no agricultural land in household. & & & & & \\
No & 5.17 & 7.21 & 5.81 & 6.29 & 8.09 \\
Yes & 4.19 & 6.83 & 4.72 & 5.76 & 7.44 \\
\hline
\end{tabular}

Source: Authors summarization based on Punyasavatsut (2017) dataset.

For the relationship between PMT Poverty score and student's average monthly household income per capita, this PMT poverty score has ranged between 0 and 100 ranking from not-poor (0) to poorest (100.) Meaning that relationship between student's household average monthly income per capita and PMT poverty score is negative, i.e., the higher the score, the lower the income. We can show this relation in Figure 1 below:

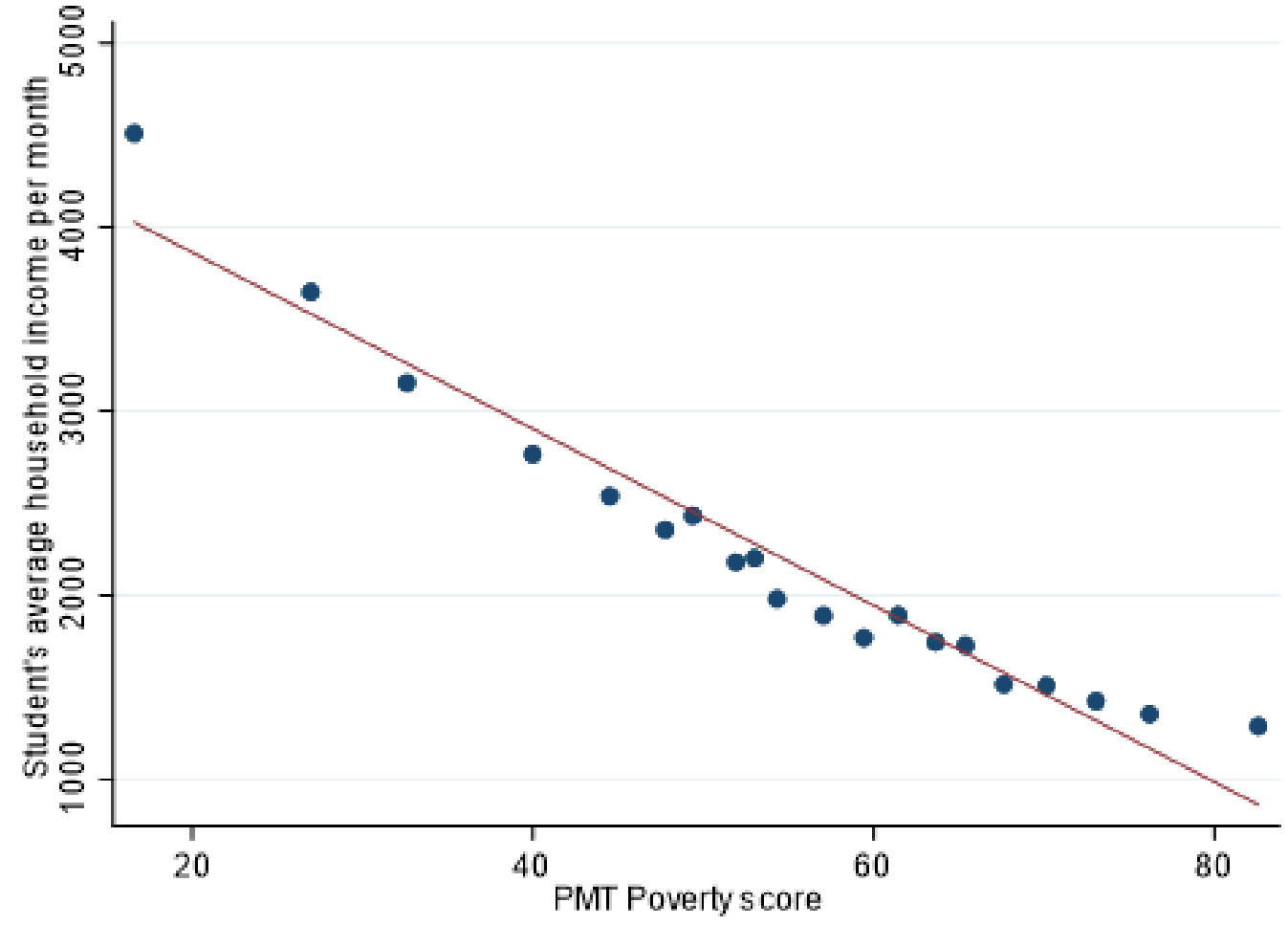

Figure 1 Source: Authors Calculation in Stata Based on Punyasavatsut (2017) dataset.

Now, we will target poor students in our test dataset, a total of 116,508 students, using PMT poverty score created in train dataset as shown in Table 7. For cutoff-score point, as PMT poverty score is a score which predicted student's average monthly income per capita, we can find an average PMT poverty score of households whose average monthly income per capita equal to poverty line at each province and set this score as a cutoff-score point for each province. Cutoff-score point for each province are shown as following Table 10: 
Table 10 CUTOFF-SCORE POINT FOR 10 PROVINCES OF THAILAND

\begin{tabular}{lll}
\hline Province & Poverty Line & Cutoff-score Point \\
\hline Mae Hong Son & 2,320 & 43 \\
Nan & 2,331 & 43 \\
Nakhon Ratchasima & 2,364 & 43 \\
Udon Thani & 2,364 & 43 \\
Nakhon Phanom & 2,402 & 43 \\
Chiang Rai & 2,552 & 42 \\
Trung & 2,798 & 41 \\
Kanchanaburi & 2,801 & 39 \\
Chanthaburi & 2,980 & 37 \\
Phuket & 3,059 & 36 \\
\hline
\end{tabular}

Source: Authors calculation based on National Economic and Social Development

Board of Thailand (NESDB) and Punyasavatsut (2017) dataset.

These cutoff-score points reflect student's average monthly household income per capita as we can see that the higher the poverty line, the lower the PMT poverty score, i.e., Mae Hong Son which has lowest poverty line will have a higher cutoff-score point comparing to Phuket which has highest poverty line and; hence, lowest cutoff-score point. The student whose PMT poverty scored above cutoff-score point will be targeted as poor students and vice versa. The result of targeting is shown in Table 11 below:

Table 11 CUTOFF-SCORE POINT FOR 10 PROVINCES OF THAILAND

\begin{tabular}{lllll}
\hline Province & Actual Poor & Actual Non-poor & Targeted as Poor & Targeted as Non-poor \\
\hline Mae Hong Son & 3,305 & 677 & 3,538 & 444 \\
Nan & 4,090 & 1,648 & 3,991 & 1,747 \\
Nakhon Ratchasima & 20,516 & 12,602 & 27,833 & 5,285 \\
Udon Thani & 13,190 & 6,511 & 15,067 & 4,634 \\
Nakhon Phanom & 12,380 & 4,122 & 13,442 & 3,060 \\
Chiang Rai & 11,417 & 3,610 & 12,077 & 2,950 \\
Trung & 2,758 & 769 & 2,906 & 621 \\
Kanchanaburi & 9,030 & 3,483 & 10,251 & 2,262 \\
Chanthaburi & 3,170 & 1,604 & 3,711 & 1,063 \\
Phuket & 768 & 858 & 1,348 & 278 \\
Total & 80,624 & 35,884 & 94,164 & 22,344 \\
\hline
\end{tabular}

Source: Authors calculation based on Punyasavatsut (2017) dataset.

From Table 11, most of all provinces have the total number of targeted as poor students greater than total number of actual poor students except for Nan province which has the opposite. Could it be the case that Nan faces an undercoverage problem while the rest 9 provinces face a leakage problem? To further our investigation, we will calculate the following 4 targeting performance measurements: Leakage rate, undercoverage rate, poverty accuracy rate, and total accuracy rate. Results are shown in Table 12: 
Table 12 CUTOFF-SCORE POINT FOR 10 PROVINCES OF THAILAND

\begin{tabular}{lllll}
\hline Province & Leakage Rate & Undercoverage Rate & Poverty Accuracy Rate & Overall Accuracy Rate \\
\hline Mae Hong Son & $12.22 \%$ & $5.17 \%$ & $94.83 \%$ & $85.56 \%$ \\
Nan & $19.12 \%$ & $21.54 \%$ & $78.46 \%$ & $71.02 \%$ \\
Nakhon Ratchasima & $44.07 \%$ & $8.41 \%$ & $91.59 \%$ & $67.49 \%$ \\
Udon Thani & $29.17 \%$ & $14.94 \%$ & $85.06 \%$ & $70.47 \%$ \\
Nakhon Phanom & $20.91 \%$ & $12.33 \%$ & $87.67 \%$ & $75.06 \%$ \\
Chiang Rai & $18.88 \%$ & $13.09 \%$ & $86.91 \%$ & $75.71 \%$ \\
Trung & $18.09 \%$ & $12.73 \%$ & $87.27 \%$ & $75.90 \%$ \\
Kanchanaburi & $25.22 \%$ & $11.69 \%$ & $88.31 \%$ & $73.36 \%$ \\
Chanthaburi & $31.26 \%$ & $14.20 \%$ & $85.80 \%$ & $69.82 \%$ \\
Phuket & $82.16 \%$ & $6.64 \%$ & $93.36 \%$ & $58.06 \%$ \\
Total & $28.80 \%$ & $12.00 \%$ & $88.00 \%$ & $71.77 \%$ \\
\hline
\end{tabular}

Source: Authors calculation based on Punyasavatsut (2017) dataset.

In overall, we found that our PMT poverty score works well in term of low undercoverage rate at around 12 percent, high poverty, and total accuracy at around 88 and 72 percent, respectively. Leakage rate; however, was quite high at around 29 percent. For PMT targeting performance in each province, we found that in Mae Hong Son, PMT poverty targeting seems to work best with lowest leakage rate at around 12 percent, lowest undercoverage rate at around 5 percent, highest poverty accuracy rate at around 95 percent and highest total accuracy rate at around 86 percent. There is high undercoverage rate; however, in Nan at around 22 percent. This, also, leads to lowest poverty accuracy rate with around 78 percent. Lastly, there is a very high leakage rate in Phuket with around 82. This, also, leads to lowest total accuracy rate with around 58 percent.

What we found from PMT poverty targeting performance is that PMT poverty targeting performs well in term of low undercoverage and high targeting accuracy but not in term of low leakage. Out of all 10 provinces, Phuket seems to have a huge geographical difference as there is a huge different gap in leakage rate comparing to Nakhon Ratchasima, the second-highest leakage rate province at around 44 percent, and others. This is, by the fact that Phuket is a small and tourist destination province in Thailand, which leads to an advantage for household in Phuket to earn more income than other provinces which could result in highly different household characteristics comparing to others. This fact is consistent with what we found in Table 3 and 11 where Phuket is the only province that has a proportion of poor students lesser than non-poor students with around 46 and 54 percent, respectively. With this difference in geographical; therefore, using the same PMT questionnaire in targeting poor students in all provinces of Thailand may not be an effective way for poverty targeting.

There is another aspect to be a concern in this high leakage rate problem, however. High leakage rate tells us two things. Firstly, by its definition, there are high number of non-poor students who have been mistargeted as poor students, but another aspect which should be concerned is that, secondly, students who have been identified as actual non-poor by using province poverty line may, in fact, poor as same as suggested by PMT poverty targeting. Consider this; although, Phuket has an income-earning advantage cost of living in Phuket also high as well. A further identification survey in these student households which has been targeted as poor by using PMT poverty targeting but non-poor by using income poverty line; therefore, could confirm to us whether this is a case of an actual leakage of PMT poverty targeting or a misidentification of poor student using income and poverty line as a measurement.

\section{CONCLUSIONS AND RECOMMENDATIONS}

In conclusion, this study is trying to create a proxy means test (PMT) poverty scorecard to be used as a tool for targeting poor students in 10 provinces of Thailand, including Mae Hong Son, Nan, Nakhon Ratchasimi, Udon Thani, Nakhon Phanom, Chiang Rai, Trung, Kanchanaburi, Chanthaburi and Phuket, using relationship between household's characteristic and student's average monthly household income per capita. As we found that student who living in rental housing has a positive effect on average monthly household income per capita in all 10 provinces of Thailand, we excluded living in rental housing from our PMT poverty scorecard. The explanation for this case is due to the fact that proportion of actual non-poor students whose household lives in rental housing is higher than the actual 
poor. Also, we do not have data on whether student who does not live in rental house owning a house of their own or living with others such as their relatives. Therefore, we only have 11 household characteristic variables in our PMT poverty scorecard as follows:

1. There is a disabled person in the household.

2. There is an elder in the household.

3. There is an unemployment person with the age of 15-65 years in the household.

4. Student stays with a single parent.

5. Student's living place is in a dilapidated condition or is made of local materials such as bamboo, leaves, etc.

6. Student's living place has no toilet in the living area.

7. Having no personal car in the household.

8. Having no Pick-up truck, small truck, or a minivan in household.

9. Having no tractor or harvester in the household.

10. Having agricultural land less than 1 rai (equivalent to 1600 square meters) in the household.

11. Having no agricultural land in the household.

After we estimated a relationship between household characteristic variables and student's average monthly household income per capita and converted our estimated coefficient into PMT poverty scorecard, rating from 0 (not-poor) to 100 (poorest,) we then, gave this score to each student in the test dataset. The student who received PMT poverty score above cutoff-score point would be targeted as poor student according to a province they habited and vice versa. We found that there are some differences in PMT poverty score in some household characteristic variables which suggested to us that there are exist of geographical difference between each province. Finally, we evaluated the efficiency of PMT poverty targeting by using 4 targeting measurements: Leakage rate, undercoverage rate, poverty accuracy rate, and total accuracy rate. For overall performance, PMT poverty targeting worked well in term of low undercoverage rate at around 12 percent and high accuracy rate with poverty accuracy at around 88 percent and total accuracy at around 72 percent, but leakage rate was high at around 29 percent. For performance in each province, we found another evidence of huge geographical difference in Phuket which has a huge difference in geographical characteristics with highest leakage rate at around 82 percent. This leakage rate problem is two sides of stories; however. It could be the case that there are actually a high number of non-poor students who have been mistargeted as poor students or it could, also, be the case that students who have been identified as actual non-poor by using province poverty line may, in fact, poor as same as suggested by PMT poverty targeting. From what we found in our study; we would like to suggest 2 aspects of recommendation:

PMT as a main poverty targeting method in Thailand: As we found in our study that PMT poverty targeting works well in term of low undercoverage with high in both poverty and total accuracy, we suggested the used of PMT as the main tool in targeting poor students in Thailand. Also, an identification survey of student who has been targeted as poor could tell us whether these students are actually poor as suggested by PMT poverty targeting or it is an actual case of a leakage problem. Using both of this method simultaneously could potentially increase accuracy in poverty targeting.

Improving PMT poverty targeting in statistical methodology: To improve the efficiency of PMT poverty targeting in statistical methodology, we would, firstly, suggest the increment of household characteristic variables in the survey questionnaire as we found that some household characteristic variables (living with single parent and living in rental housing) have problem in predicting household income. This may due to the fact that we have omitted some of data on household characteristic from our model, including variables such as remittance variables and type of housing could increase our PMT poverty targeting performance.

Finally, for further study, we would recommend creating a PMT poverty scorecard for all 77 provinces of Thailand to investigate more about the difference in geographical characteristics between each province. Also, an 
increase in household characteristic variables in PMT could improve the efficiency of PMT poverty targeting. If possible, we would, also, recommend further researcher to conduct their own identification survey of student who has been targeted as poor student to understand in-depth detail about a leakage and poverty mistargeting problem.

\section{REFERENCES}

Ahmed, A. U., \& Bouis, H. E. (2002, oct). Weighing what's practical: Proxy means tests for targeting food subsidies in Egypt. Food Policy, 27(5-6), 519-540. doi:https://doi.org/10.1016/s0306-9192(02)00064-7

Bah, A., Bazzi, S., Sumarto, S., \& Tobias, J. (2018). Finding the poor vs. measuring their poverty: Exploring the drivers of targeting effectiveness in Indonesia. The World Bank Economic Review, 33(3), 573-597. doi:https:// doi.org/10.1093/wber/lhx020

Baird, S., Ferreira, F. H., Özler, B., \& Woolcock, M. (2014). Conditional, unconditional and everything in between: A systematic review of the effects of cash transfer programmes on schooling outcomes. Journal of Development Effectiveness, 6(1), 1-43. doi:https://doi.org/10.1080/19439342.2014.890362

Bakhshoodeh, M. (2013). Proxy means tests for targeting subsidies scheme in Iran. Iranian Journal of Economic Studies, 2(2), 25-46. doi:https://doi.org/10.1016/0306-9192(92)90015-P

Edirisinghe, N. (1987). The food stamp scheme in Sri Lanka: Costs, benefits, and options for modification (Vol. 58). Washington, DC, WA: Intl Food Policy Res Inst.

Glewwe, P., Kanaan, O., et al. (1989). Targeting assistance to the poor using household survey data. Washington, DC, WA: The World Bank.

Grosh, M. (1992). The Jamaican food stamps programme: A case study in targeting. Food Policy, 17(1), 23-40. doi:https://doi.org/10.1016/0306-9192(92)90015-P

Grosh, M. (1994). Administering targeted social programs in Latin America. Washington, DC, WA: The World Bank.

Grosh, M., \& Baker, J. L. (1995). Proxy means tests for targeting social programs. Washington, DC, WA: The World Bank.

Grosh, M., \& Glinskaya, E. (1997). Proxy means testing and social assistance in Armenia (Tech. Rep.). Washington, DC, WA: Development Economics Research Group, The World Bank.

Haddad, L., Kennedy, E., \& Sullivan, J. (1994). Choice of indicators for food security and nutrition monitoring. Food Policy, 19(3), 329-343. doi:https://doi.org/10.1016/0306-9192(94)90079-5

Houssou, N., Zeller, M., Alcaraz, V., Schwarze, S., Johannsen, J., et al. (2007). Proxy means tests for targeting the poorest households-Applications to Uganda. In 106th Seminar of European Association of Agricultural Economists (EAAE) (p. 2-25). Montpellier, France. Retrieved from https://bit.ly/2kB8D8L

IRIS. (2005). Developing poverty assessment tools project: Note on assessment and improvement of tool accuracy (Report). Morrill Hall, MD: IRIS Center, University of Maryland.

Kambuya, C. (2017). Better model selection for poverty targeting through machine learning: A case study in Thailand (Unpublished master's thesis). Bangkok, Thailand: Thammasat University.

Kshirsagar, V., Wieczorek, J., Ramanathan, S., \& Wells, R. (2017). Household poverty classification in data-scarce environments: A machine learning approach. In 31st Conference on Neural Information Processing Systems (NIPS 2017). Long Beach, CA.

Narayan, A., \& Yoshida, N. (n.d.). Proxy means tests for targeting welfare benefits in Sri Lanka (Reprort No. SASPR-7). Washington, DC, WA: The World Bank. Retrieved from https://bit.ly/2lMhjct

Paireepinas, D. A., P., \& Grisanaputi, W. (2017). Lifelong learning management for the urban poor: A case study of Khon Kaen city, Thailand. Journal of Advanced Research in Social Sciences and Humanities, 2(5), 321-329. doi:https://doi.org/10.26500/jarssh-02-2017-0505

Punyasavatsut, C. (2017). The development of information system for learning opportunities insurance (Tech. Rep.). Bangkok, Thailand: Economic Research and Training Center (ERTC), Faculty of Economics, Thammasar University.

Purwanto, \& Purba, C. S. (2017). Legal aid compliance for poor local community. Journal of Advanced Research in Social Sciences and Humanities, 2(6), 363-370. doi:https://doi.org/10.26500/jarssh-02-2017-0604

Schreiner, M. (2008a). A simple poverty scorecard for India. Citeseer. Retrieved from https://bit.ly/2mi8Huu 
Schreiner, M. (2008b). Simple poverty scorecard poverty-assessment tool-Ecuador. Retrieved from https://bit.ly/ 2 miiv $7 \mathrm{~N}$

Schreiner, M. (2009). A simple poverty scorecard for the Philippines (Report). Quezon City, Phillipines: Philippine Institute for Development Studies. Retrieved from https://bit.ly/2ma9VYv

Schreiner, M. (2010a). A simple poverty scorecard for Honduras. Retrieved from https://bit.ly/2kkcZ3V

Schreiner, M. (2010b). A simple poverty scorecard for Pakistan. Journal of Asian and African Studies, 45(3), 326-349. doi:https://doi.org/10.1177/0021909609353579

Schreiner, M. (2011). A simple poverty scorecard for Uganda. Retrieved from https://bit.ly/21U2698

Schreiner, M. (2012a). A simple poverty scorecard for Paraguay. Retrieved from https://bit.ly/2mhpVrS

Schreiner, M. (2012b). A simple poverty scorecard for Peru. Retrieved from https://bit.ly/2kM5jr9

Schreiner, M. (2012c). Simple poverty scorecard poverty-assessment tool: Colombia. Retrieved from https://bit.ly/ $2 \mathrm{~m} 9 \mathrm{fMxc}$

Schreiner, M. (2013). Simple poverty scorecard poverty-assessment tool: Bangladesh. Retrieved from https://bit.ly/ $2 \mathrm{miiYqz}$

Schreiner, M. (2016). Simple poverty scorecard poverty-assessment tool: Guatemala. Retrieved from https://bit.ly/ 2lV6Awd

Sharif, I. (2009). Building a targeting system for Bangladesh based on proxy means testing. Washington, DC, WA: Human Development Network, The World Bank. 